\title{
Automated Shopping Trolley Using Raspberry Pi Device
}

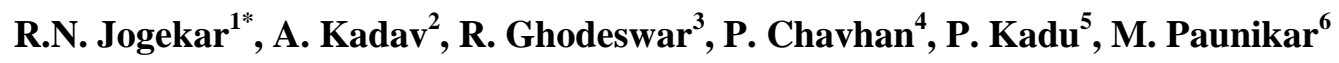 \\ ${ }^{1 *}$ Dept. of CSE, Priyadarshini J.L. College of Engineering, RTMNU, Nagpur, India \\ 2,3,4,5,6 Dept. of CSE, Priyadarshini J.L. College of Engineering, RTMNU, Nagpur, India \\ "Corresponding Author: ravindra.jogekar79@gmail.com, Tel.: +91-8087770221
}

Available online at: www.isroset.org

Received: 15/Mar/2018, Revised: 22/Mar/2018, Accepted: 05/Apr/2018, Online: 30/Apr/ 2018

\begin{abstract}
With the development of wireless technology there are various fields wherein we can use this technology and use of wireless technology is favorable now a days. In this paper we present our views on an automated shopping trolley using raspberry pi device combined with bar code scanner and LCD display. As we know that during sales and holidays we observe rush at supermarkets and due to this billing process becomes more time consuming and customer cannot stand for too long in a queue for billing purpose so, here we can makes use of the automated shopping trolley which has barcode scanner, raspberry pi and LCD display. Using this trolley the customer will self scan the product by himself and prepare the bill. Hence, there will be no long queue in the supermarket at billing counter for billing purpose.
\end{abstract}

$\underline{\text { Keywords - Raspberry pi device, Barcode Scanner, LCD display Smart Trolley. }}$

\section{INTRODUCTION}

With the increasing needs of humankind there is the need for development of new technology to make day to day work easy and effortless. Shopping is one of the thing in which we spend considerable amount of time and to know charge of money for goods is a time consuming process due to standing in a long queue for billing process. In this paper we have proposed the shopping trolley. This trolley is not similar to the trolley we use now a days. It is the newer and innovative version of the basic trolley. This smart trolley consists of raspberry pi, barcode scanner, LCD display with Wi-Fi connection.

With the help of barcode scanner which is present at the trolley connected with the raspberry pie and supermarkets database through Wi-Fi the customer can self-scan the product and aware of total cost of the bill as the overall information is display on the screen which is integrated on the trolley itself. The purpose of the raspberry pi is to operate the overall system .It works as a mini computer.

Now, further after completing the shopping customer will go to the billing counter only for payment and as the overall total bill is already displayed on the LCD screen which is connected to raspberry pie and customer is already aware about total bill. This system is also beneficial for the customer who has certain budget limit. This automated shopping trolley will provide customer satisfaction as the customer will not stand in a long queue to know the total charge for goods he/she purchased.
The organization of the paper is as follows, Section I contains the introduction of Automated shopping trolley using raspberry pi device, Section II contains the related work of Automated shopping trolley, Section III contains the architecture and proposed system of automated shopping trolley, Section IV concludes research work with future directions.

\section{LITERATURE SURVEY}

RFID Based Automated Billing Trolley (by Galande Jayshree, Rutuja Gholap, Preeti Yadav)

In this paper they have used concept of RFID tags and RFID reader to scan the products and get the bill of total number of item purchased. But the RFID systems are more expensive than barcode system and it can be less reliable. To overcome this drawback we have used the concept of automated shopping trolley using raspberry pi and barcode scanner with LCD display, it consist barcode instead of RFID tags. The customer will scan the barcode instead of RFID tags. Also with the use of barcode we do not need to attach separate tags to the products, barcode is printed on the product itself.

Ingenious Shopping Cart: RFID Enabled For Automated Billing (by Tanushree, Siddharth Yadav,

Saksham Aggarwal, Sagar, Mohit Yadav, Neeraj Gupta, Shruti Karkra) 
In this paper they have proposed a system in which RFID tags are attached with products and that tags are read by the RFID reader. But in this system it may happen that more than one RFID tag can respond at the same time. Also, RFID tags are usually larger than barcode. To overcome this drawback we use barcode and barcode scanner which is more efficient.

\section{ARChitecture OF Proposed System}

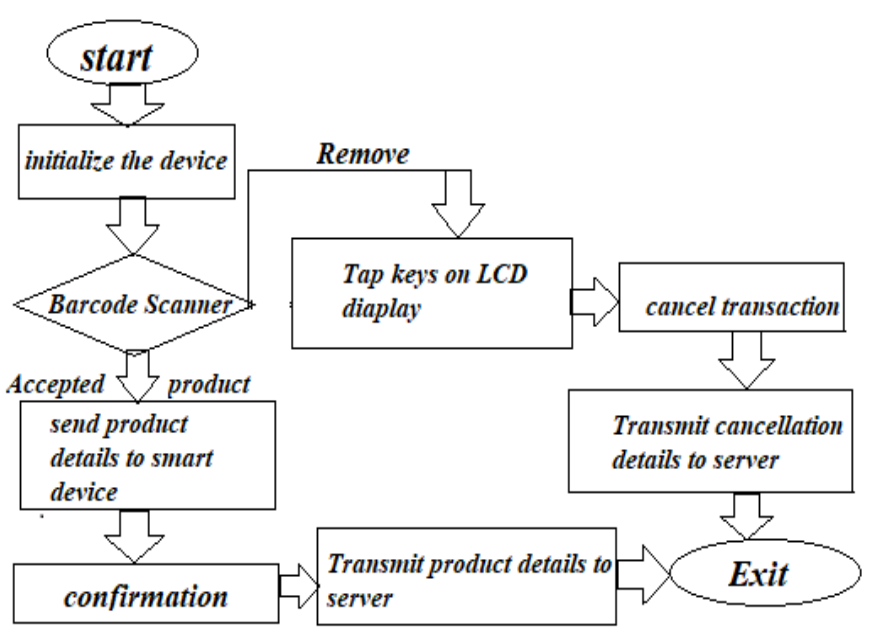

Fig 1: Architecture of Automated Shopping Trolley

1. Whenever the customer wants to purchase the items they simply pick up the item from the supermarket shelf and scan the product with the help of barcode scanner, which is integrated on a shopping trolley.

2. Every product or item has the unique barcode id.

3. After purchasing the product if the customer wants to remove the unwanted product then they can easily remove the products by clicking on the deduct button present on the screen.

4. The overall information of the products which is purchased by the customer is display on LCD screen; it contains the information such as price, total number of item and total bill.

5. As the device is connected to the database backend through Wi-Fi, the overall information is also display on the administrator side.

6 . Hence, after completing the shopping the customer has to pay the bill and no need to stand in a long queue.

\section{Conclusion ANd Future Scope}

This research paper will help the people to reduce manpower required in billing section. This can reduce the expenses incurred by the management. Users can be aware of the total bill amount during the time of purchase.
In future this system will also increase customer satisfaction which will be beneficial for supermarket owner as well as the customer.

\section{REFERENCES}

[1]. Kalyani Dawkhar, Shraddha Dhomase, Samruddhi Mahabaleshwarkar "Electronic Shopping Cart for Effective Shopping based on RFID", International Journal of Innovative Research in Electrical, Electronic, Instrumentation and Control Engineering Vol. 3, Issue 1 pp 84-86, January 2015.

[2]. Zeeshan Ali, Reena Sonkusare, "RFID Based Smart Shopping and Billing ", International Journal of Advanced Research in Computer And Communication Engineering, Vol. 2, Issue 12, December 2013

[3]. Raju Kumar, K. Gopalakrishna, K. Ramesha, "Intelligent Shopping Cart," International Journal of Engineering Science and Innovative Technology (IJESIT) Volume 2, Issue 4, July 2013.

[4]. Ekta Maini and Jyoti Shettar Wireless Intelligent Billing Trolley for Malls, International Journal of Scientific Engineering and Technology Volume No.3 Issue No.9, pp: 1175-1178.

[5]. Satish Kamble, Sachin Meshram, Rahul Thokal, Roshan Gakre "Developing a Multitasking Shopping Trolley Based On RFID Technology", International Journal of Soft Computing and Engineering (IJSCE), Volume-3, Issue-6, January 2014.

[6]. Rahmani.E, "Zigbee/IEEE 802.15.4", University of Tehran, 2005.

[7]. Galande Jayshree, Rutuja Gholap, Preeti Yadav "RFID Based Automatic Billing Trolley, International Journal of EmergingTechnology and Advanced Engineering Volume 4, Issue 3, March 2014.

[8]. Ergen, S. C., "ZigBee/IEEE 802.15.4 Summary," EECS Berkely, September.

[9]. RFID based automated billing trolley (by Galande Jayshree, Rutuja Gholap, Preeti Yadav) Ingenious shopping cart: RFID enabled for automated billing (by Tanushree, Siddharth Yadav, Saksham Aggarwal, Sagar, Mohit Yadav, Neeraj Gupta, Shruti Karkra)

\section{Authors Profile}

Ravindra Jogekar, $\mathrm{He}$ is working as an Assistant Professor of Computer Science and Engineering department of Priyadarshini J L College of Engineering. His intrests of reaseach is in, Artificial Intelligence, Database and Data warehousing \& mining, Computer Network, Computer Graphics, Software Engineering, Data Structure.

Anjali Kadav is pursuing her Bachelor of Engineering in Computer Science from Priyadarshini J.L. College of Engineering, Rashtrasant Tukadoji Maharaj Nagpur University, Nagpur-440009, India

Ruchita Ghodeswar is pursuing her Bachelor of Engineering in Computer Science from Priyadarshini J.L. College of Engineering, Rashtrasant Tukadoji Maharaj Nagpur University, Nagpur-440009, India
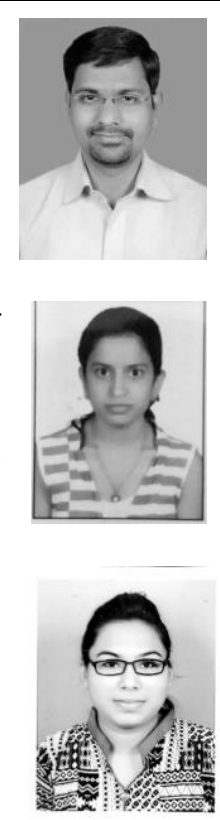
Priyanka Chavhan is pursuing her Bachelor of Engineering in Computer Science from Priyadarshini J.L. College of Engineering, Rashtrasant Tukadoji Maharaj Nagpur University, Nagpur-440009, India

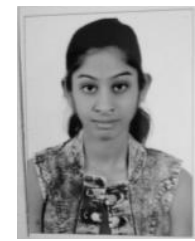

Payal Kadu is pursuing her Bachelor of Engineering in Computer Science from Priyadarshini J.L. College of Engineering, Rashtrasant Tukadoji Maharaj Nagpur University, Nagpur-440009, India

Monika Paunikar is pursuing her Bachelor of Engineering in Computer Science from Priyadarshini J.L. College of Engineering, Rashtrasant Tukadoji Maharaj Nagpur University, Nagpur-440009, India

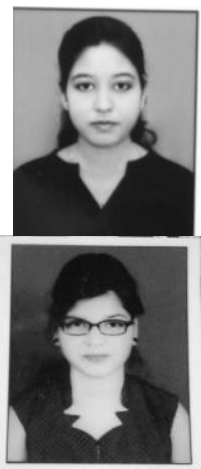

